\title{
Situação do professorado em Portugal: identidades fragmentadas entre a paixão e o desencanto
}

\author{
Teacher's situation in Portugal: \\ fragmented identities between passion and disenchantment \\ Situación del profesorado en Portugal: \\ Identidades fragmentadas entre la pasión e el desencanto
}

MARCO CORRIENTE ROSA*

\begin{abstract}
$\diamond$
\section{RESUMO}

Neste artigo, discute-se a situação profissional do professorado em Portugal em torno da análise das transições mais recentes e dos seus impactos sobre os docentes, designadamente o processo de abordagem da crise económica e financeira. Os resultados que se apresentam numa estratégia de investigação qualitativa, centram-se em implicações emocionais na forma como os docentes vivem a sua profissão, através das suas próprias narrativas.
\end{abstract}

Palavras-chave: Professorado. Mudança. Crise. Paixão. Desencanto.

\section{Abstract}

This paper discussed the professional status of teachers in Portugal and revolves around the analysis of the latest transitions and their impact on teachers, namely the approach to the economic and financial crisis. The results presented, a qualitative research strategy, focus in the emotional implications for the way they live your profession through their own narratives.

Keywords: Teachers. Change. Crisis. Passion. Disenchantment.

\section{RESUMEN}

En este trabajo se discute la situación del profesorado en Portugal y se basa en el análisis a las transiciones más recientes y en sus impactos sobre los docentes, en este caso, sobre el proceso de abordaje a la crisis económica y financiera. Los resultados que se presentan, por medio de una estrategia de investigación cualitativa, se centran en las implicaciones emocionales en la manera como los docentes viven su profesión, a través de sus propias narrativas. Palabras clave: Profesorado.Cambio. Crisis. Pasión. Desencanto. 


\section{INTRODUÇÃO}

$\mathrm{O}$ presente artigo enquadra-se nas abordagens sobre as condições em que o professorado desenvolve o seu trabalho e na forma como o contexto social e político condiciona as suas vivências e altera a forma como sente e vive a profissão, a partir da construção das identidades profissionais. As transformações que ocorreram recentemente, em Portugal, por via das opções políticas para a gestão da crise económica e financeira, trouxeram à superfície um conjunto de situações que se implicam naquilo que é o processo multidimensional, idiossincrático e contextual no qual os profissionais docentes se confrontam. Um conjunto de dilemas e paradoxos que se pretende compreender em profundidade, sendo que para tal se recorre a uma abordagem qualitativa de caráter narrativo e interpretativo. Os resultados que a seguir se apresentam fazem parte de um projeto de investigação mais amplo, que caracteriza o ambiente em que a profissão docente se desenvolveu nos últimos anos. Isto é, os contextos determinados pelos desígnios sociais e políticos e que adornaram o cenário em que se desenvolveu a pesquisa.

\section{CONTRIBUTOS PARA O CONCEITO DE IDENTIDADE PROFISSIONAL}

A discussão sobre identidades profissionais não se reduz aos discursos oficiais e políticos, pois essa classe profissional caracteriza-se numa dimensão mais complexa do que a de meros formadores de cidadãos e cidadãs. As identidades profissionais são construídas em contexto e em transição ecológica, onde interagem a história, familiar e pessoal, e as condições de trabalho. Os discursos oficiais falam, apenas, daquilo que são as suas funções. Quando se trata de sujeitos sociais que partilham espaços, tempos e representações sociais na e sobre a escola, não se pode deixar de considerar que o contexto mais amplo em que cada um dos sujeitos está inserido interfere profundamente nas suas expetativas e perceções E é essa complexidade que se pretende compartilhar.

Para Day et al. (2006), a identidade profissional passa pela conceção pessoal e profissional da pessoa do docente e é representada pelas diferentes perspetivas históricas e culturais nos diferentes contextos em que ocorrem as mudanças. E as noções de identidade docente têm de ser particularizadas por aquilo que são os desafios das suas vidas pessoais e profissionais, ou seja, a identidade tem de ser sempre problematizada a partir dos campos conceptuais do trabalho e da própria vida.

Pode-se entender, de acordo com Garcia et al., que essa construção social é caracterizada e marcada por múltiplos fatores que interagem entre si e que resultam nas representações que os docentes possuem em relação a si mesmos e às suas funções. estabelecem, assim, de forma consciente ou inconsciente, "negociações das quais certamente fazem parte suas histórias de vida, suas condições concretas de trabalho, o imaginário recorrente acerca dessa profissão" (GARCIA et al., 2005, p.54). Imaginário esse que é condicionado pela génese e pelo desenvolvimento histórico da profissão e também pelas marcas socioculturais deixadas pelos discursos acerca do professorado, em particular e, de uma forma geral, da escola.

Segundo Esteve (2006), os profundos processos de mudança social registados nas últimas três décadas e os consequentes efeitos nos sistemas educativos colocaram novos problemas, os quais ainda não foram totalmente assimilados. Alguma desorientação, associada ao défice de formação para assumir novos desafios, e a tentativa, quase desesperada, para manter as rotinas, leva a que, numa grande amplitude, muitos profissionais realizem um trabalho desadequado, enfrentando uma crítica generalizada que os considera como os responsáveis universais por todas as falhas do sistema educativo.

Para Lawn (2001), as mudanças que acabámos de referir podem ser explicadas em três aspetos: (i) a identidade dos/as docentes deve adaptar-se à conceção de educação da nação; (ii) uma das formas de acompanhar a escola e os professores é criando mecanismos, através do discurso oficial, que sejam capazes de monitorizar e controlar a identidade docente e, por fim; (iii) a identidade do professorado pode, de forma sub-reptícia, ser manobrada a favor de interesses, que não são, necessariamente, os do coletivo profissional e da restante comunidade educativa, daqueles que partilham o espaço escolar.

Refere-se, por isso, em concordância com Garcia et al., que a identidade é um constructo em ação na análise da docência, entendendo-se, por identidade profissional, "as diferentes posições de sujeito que são atribuídas por diferentes discursos e agentes sociais (...) no exercício de suas funções em contextos laborais concretos" (2005, p. 48). Temos de incluir, ainda, o conjunto das representações colocadas em circulação pelos discursos relativos aos modos de ser e de agir do professorado no exercício das suas funções em contextos escolares, em toda a sua complexidade e natureza mais ou menos burocrática.

A antiga imagem da profissão docente como símbolo da autoridade e da providência moral tem sido substituída pela imagem de um adversário a ser derrotado pelo aluno. Por outro lado, a imagem da escola como ambiente seguro, onde crianças e jovens poderiam desenvolver os valores morais e democráticos, é substituída pela imagem de um território conflagrado. E a imagem de um aluno, como 
sujeito em construção a ser encaminhado para a vida em sociedade, é substituída por uma imagem de rebeldia. Os extremos dessas representações não deixam dúvidas de que as expetativas em relação à escola mudaram consideravelmente (BOIA, 2003).

Naquilo que são as disputas em torno de várias conceções, de identidade, de profissionalismo e de profissionalização, não se pode obviar o fenómeno do controlo subjacente sobre os processos de trabalho e sobre os significados que circulam ou que podem circular no âmbito da educação, conforme refere Lawn (2001, p. 118),

A gestão da identidade dos professores é crucial para a compreensão, quer de sistemas educativos democráticos, quer totalitários (...) as alterações na identidade são manobradas pelo Estado, através do discurso, traduzindo-se num método sofisticado de controlo e numa forma eficaz de gerir a mudança.

Hypolito $(2003 ; 2009)$ (re)equaciona o trabalho docente através de formas coletivas de o exercer, que considerem os saberes (docentes) teóricos e práticos e que, simultaneamente, considerem as comunidades escolares como parte integrante de uma construção do processo educativo. Segundo esse autor, o profissionalismo tem de significar a melhoria do trabalho profissional e também a melhoria da qualidade social do ensino. E esta tem de ser enriquecida a partir dos contributos das comunidades, dos grupos e dos movimentos sociais, que considerem as identidades étnicas, de género e de classe de quem usufrui da educação, como função social, desconstruindo o conceito de clientes, como é veiculado pelo neoliberalismo. Assim, o conceito de identidade profissional tem de incluir a sensibilidade política para lidar com as definições do currículo, em que conteúdos e métodos devem resultar menos de uma sabedoria iluminada do profissional e depender mais do interrelacionamento com as realidades culturais nas quais se inscrevem os processos educativos.

Postas essas visões sobre a construção de identidades na docência, pode-se considerar que esta deve ser entendida como uma construção social, marcada por vários fatores que interagem de forma sistémica e que resultam nas representações que os docentes constroem sobre si próprios e sobre o seu trabalho, num processo relacional e biográfico (DUBAR, 1991).

\section{O CONTEXTO}

A crise financeira, com raízes na década de 1970, tornou-se visível, em particular desde 2008, criando situações favoráveis para o desenvolvimento de políticas neoliberais. Em Portugal, essa crise atinge a sua expressão máxima em 2011. Foi nesse ano que o governo em funções ${ }^{1}$ pediu ajuda externa, sendo executado um programa de assistência por uma troika que impôs medidas de austeridade com um alcance e impacto tremendo. O que repercutiu, de modo muito acentuado, pela generalidade da sociedade portuguesa.

Imposta por instâncias internacionais, a que se aliou um governo de direita, a austeridade desencadeou medidas devastadoras nas áreas sociais do Estado (BENAVENTE et al., 2015) e, no caso que se abordou presentemente, no sistema educativo e na profissão docente.

De uma forma geral, concorda-se com a autora, quando se refere que há elementos no contexto mundial que favoreceram e favorecem políticas de retrocesso à escola tradicional: "A escola das notas e dos exames, da seleção e da exclusão" (2015, p. 19). Uma leitura feita a partir do discurso paradigmático do Ministério de Educação e Ciência (MEC) e que transporta a escola para uma linguagem de um passado de ditadura fascista, que teve o seu ocaso em abril de 1974. As medidas e o discurso sobre as políticas educativas em Portugal trazem fortes reminiscências a tempos de outrora. De resto, uma retórica que não se pode atribuir apenas a partidos da oposição, pois muitas são as vozes que se fazem ouvir. E o exemplo concreto é o incontornável António Nóvoa ${ }^{2}$, citado em notícia do Jornal Público como uma das vozes mais críticas às atuais políticas educativas:

\section{As "práticas seletivas" baseadas em exames, as "políticas de privatização do ensino", as "estratégias de desvalorização da formação docente". E usou várias vezes a palavra liberdade - liberdade "de uma escola que tem de abrir novos mundos e não fechar a criança nos mundos que já conhece”.}

O discurso dominante atribui à escola uma conceção de fator de empregabilidade, que neste momento assenta num mundo perfeitamente desregulado e dominado pela finança, com um menosprezo preocupante pela formação crítica e cívica das novas gerações.

Portugal faz parte de um todo, ou de uma maioria, em que as políticas públicas são fortemente induzidas por diretrizes, normas e modelos de ordem transnacional, cuja ideologia económica e social se pretende hegemónica, em que as agências e organizações internacionais se encarregam de uniformizar através dos seus relacionamentos com os Estados (BENAVENTE et al., 2015).

Ainda de acordo com as mesmas autoras, a ideologia dominante, enquadrada num modelo de economia de

\footnotetext{
${ }_{1}$ Governo de coligação constituído pelo PSD e pelo CDS/PP - partidos que no panorama político português se assumem como percurssores do pensamento de direita.

2 Jornal Público de 21/03/2015.
} 
mercado global, assume que a escola tem um papel a cumprir em conformidade com os princípios dessa mesma economia e, nessa lógica, deve-se organizar, orientar e hierarquizar em todos os níveis de escolaridade. Não é, portanto, ao acaso que no seu discurso são repetidos, vezes sem conta, chavões como mercado, empreendedorismo, competências, competitividade, entre outros.

O recurso a mecanismos sofisticados de controlo passa a ter uma ligação muito direta entre objetivos e resultados obtidos por valores mensuráveis, através de diversos instrumentos, resultados de exames, rankings, recurso a meios estatísticos e comparabilidades. Com a imposição de tendências e prioridades, normaliza-se, em meio escolar, a componente seletiva assente no pressuposto da inevitabilidade e das desigualdades sociais, fomentando-se o individualismo e a competição como motores do sucesso pessoal (BOIA, 2003).

Uma das possíveis leituras do processo de gestão da crise em Portugal é que a mesma se transformou num instrumento de dominação, pois serve para legitimar decisões políticas e económicas que amputam nos cidadãos o direito a um exercício de participação que os define enquanto tal, afastando-os de todas as possibilidades de decisão.

\begin{abstract}
Nunca como agora o desígnio, assumido pelo país como estado membro da UE, da construção de um espaço europeu comum de educação nos impôs uma posição tão claramente periférica, subalterna e tão exposta a deficit democrático. $\mathrm{O}$ alinhamento dos decisores políticos com a agenda hegemónica supranacional encontra na crise um aliado na defesa de medidas que nos conduzem perigosamente a uma regressão social (BENAVENTE et al, 2015, p. 50-51).
\end{abstract}

Segundo SANTOS (2014), a tensão entre capitalismo e democracia não é facto recente. Em grande medida, a função do Estado numa sociedade capitalista seria tentar equalizar as demandas de lucro que esse sistema exige e as necessidades dos cidadãos. Enquanto os grupos marginalizados lutam por inclusão social, as empresas disputam espaço dentro do mercado de bens e serviços. Essa dinâmica deve ser administrada pelo Estado através do contrato social, na medida em que é esse mesmo contrato que "regula a tensão entre regulação social e emancipação, entre ordem e progresso" (SANTOS, 2007, p. 86).

As demandas políticas que advêm das exigências da economia capitalista em crise entram pela porta da escola e instalam-se, assumindo a forma e o conteúdo dos processos de subordinação hierárquica (BENAVENTE et al., 2015).

Para concluir esse enquadramento de crise, referemse duas notas, a primeira, lembrando Touraine (2010), que ao analisar o processo de crise considera que a mesma separa a economia da sociedade, dividindo-a em dois: os que sofrem uma crescente exclusão social, sendo surpreendente o seu silêncio, e os que se posicionam a favor de orientações culturais e éticas orientadas para os direitos humanos. Numa segunda nota, a referência a Santos, que afirmou que "não é difícil prever que vamos assistir a três fenômenos próprios deste processo de crise: o aumento de desemprego, o aumento do número de horas de trabalho dos que estão empregados e a erosão do trabalho com direitos" (2011, p. 63). O que veio a se confirmar, sem sombra de dúvida, nos aspetos gerais da sociedade portuguesa e também na profissão docente, num contexto mais restrito. Mas, literalmente, nos mesmos moldes, através de medidas concretas que tiveram um forte impacto na educação, com a restrição de recursos, designadamente a redução drástica do número de docentes, que ultrapassou os $30 \%$, na precariedade que trouxe às suas vidas e no modo como passaram a interpretar a sua função.

\section{Pesquisa - Questões, metodologia E PROTAGONISTAS}

Os dados a serem exibidos e explorados decorrem de um projeto de investigação mais amplo, que procurou conhecer e compreender quais os impactos das transições mais recentes na profissão docente, mais particularmente, na abordagem e na gestão do governo português ao processo de crise económica e financeira. Dessa forma procurou-se esclarecer de que forma o docente manifesta intenções de abandono precoce da profissão.

Essas informações foram recolhidas junto de docentes que exercem a a sua atividade profissional no sistema de ensino público em Portugal. Para o efeito, foram realizadas dez entrevistas (E) semiestruturadas e dois grupos de discussão (GD), para os quais se utilizou o mesmo guião, envolvendo um total de 23 participantes. A utilização dessas técnicas permitiu recolher um manancial de informação, a partir do qual se pretendeu chegar a um entendimento profundo e, até, a uma dimensão subjetiva dos participantes (seja no plano individual ou coletivo) e dos fenómenos. Dirigiu-se a intenção da pesquisa para grupos reduzidos, mas a serem intensamente estudados (DENZIN e LINCOLN, 2006).

Nesse caso, considerou-se pertinente seguir uma metodologia de investigação qualitativa, interpretativa e descritiva, pois entendeu-se que seria a mais adequada para perceber os processos e os fenómenos inerentes à problemática desta investigação que versa sobre a situação profissional do professorado em Portugal. Designadamente, na forma como encara os impactos das 
medidas do governo para fazer face à crise económica e financeira. Assim, pretendeu-se efetuar uma investigação acerca "das ideias, da descoberta dos significativos inerentes ao próprio indivíduo, já que ele é a base de toda a indagação" (PACHECO, 1995, p. 16).

O paradigma interpretativo assenta em posições fenomenológicas e interpretativas, assumindo uma importância ainda maior quando se trata de investigações que incidem sobre os pensamentos de sujeitos como refere Geertz (1973, CIT IN BOGDAN e BIKLEN, 1994). E o que os fenomenologistas enfatizam é a componente subjetiva do comportamento das pessoas. Tentam penetrar no mundo conceptual dos indivíduos, para o compreender, saber de que forma o constroem e quais os significados que se atribuem para os acontecimentos das suas vidas quotidianas.

A dimensão fenomenológica parte do mundo conhecido, do qual se faz uma análise descritiva com base nas experiências vividas. Do mundo conhecido e das experiências intersubjetivas obtêm-se sinais e indicações para interpretar a diversidade dos símbolos, a partir dos quais é possível interpretar os processos e estruturas sociais em curso (HUSSERL, 1982). Essa fenomelogia pode ser de particular utilidade para a interpretação de acontecimentos e processos em estudo, pois permite captar o sentido dos fenómenos e a intenção das atividades sociais. Trata-se de descobrir a realidade vivida por outras pessoas (RICOEUR, 2009).

De acordo com Bogdan \& Biklen (1994), a natureza qualitativa do estudo também é assumida, quando se pretende enfatizar a descrição, a indução, a teoria fundamentada e o estudo das perceções pessoais. O que se consubstancia no sentido atribuído aos fenómenos sociais, em que se parte da estrutura do conteúdo e da interpretação da realidade a partir do seu significado subjetivo. Esse sentido subjetivo reveste-se duma conotação social enquanto interpretação de outras pessoas.

A opção estratégica da presente investigação assentará na análise dos aspetos em estudo, configurando-se num contínuo metodológico que facilitará o processo de apreciação de dados e sua interpretação (MILES e HUBERMAN, 1994). Esse processo foi-se desenvolvendo através de um método dedutivo, a partir dos tópicos que elaborámos e, também, num processo indutivo, atribuindo valor aos dados que iam imergindo. O que ocorreu em duas fases: numa análise vertical (MILES e HUBERMAN, 1994), a partir do discurso de cada participante; e numa análise horizontal ou comparativa, com recurso a comparações constantes (GLAUSER e STRAUSS, 1967). A intenção era encontrar temas comuns e distintivos, procurando triangular os dados dessas diferentes técnicas qualitativas de recolha.

\section{NARRATIVAS DE CRISE - IMPLICAÇÕES EMOCIONAIS NA FORMA COMO OS DOCENTES VIVEM A PROFISSÃo}

As mudanças, com tudo o que envolvem, trazem implicações emocionais que condicionam e alteram a autoperceção do significado afetivo da profissão, nomeadamente quando se alteram contextos e aspetos que deslocam as motivações de outrora. É com esse pano de fundo que se coloca a questão de como se sente e se vive a profissão atualmente.

A análise dos discursos induz a se pensar que, aparentemente, o que leva os participantes a um descomprometimento com a profissão é o desencanto, pois sentem que não são devidamente valorizados. Apesar disso, a deontologia fala mais alto e, embora demonstre a intenção de um menor empenho profissional, a realidade dos factos nega-o, pois reencontra nos alunos o sentido e o gosto pela profissão. E é nessa dimensão que se reconciliam com o compromisso profissional.

\begin{abstract}
"Imagina, eu dou as aulas e sinto-me revoltado e digo: eu vou levar isto sem seriedade. Digo muitas vezes, mas não o faço. Dou o meu melhor nas aulas, faço o meu trabalho com competência e a garantia que tenho é que no ano seguinte estou na rua! Passa-se isso em todas as escolas onde tenho estado. Felizmente, se há alguma qualidade é à custa do trabalho dos professores, senão não estaríamos na lama, estaríamos numa pocilga." (E2.1)
\end{abstract}

No exemplo seguinte,, pode-se constatar a mesma tendência, encontrando revolta por aquilo que é a intensificação das relações de subordinação hierárquica e, ao mesmo tempo, o sentido do compromisso com os alunos.

Para mim, o essencial é, apenas e tão só, a relação com os meus alunos e o facto de conseguir com que eles aprendam mais qualquer coisa todos os dias. Aí vou conseguindo fazer algum esforço todos os dias porque sinto que há feedback. Todo o resto é profundamente desmotivador, portanto, eu tenho que criar uma bolha na minha cabeça que diz: este é o Fernando (nome fictício) professor dos meninos. Acabou! O resto é exclusivamente virado para outras coisas, portanto, no meu mundo de professor, tirando aquilo que são as coisas estritamente necessárias, as correções, essas coisas todas, tirando o meu trabalho pedagógico, o meu objetivo é desligar de tudo. Desligar das coisas que me preocupavam anteriormente, as relações com os colegas, as relações com a tutela, todas essas preocupações, todo esse lixo, eu digo lixo porque não interessa, isso vai para a reciclagem rapidamente, essa é a maneira pela qual eu tento manter-me saudável. É uma estratégia de defesa, claro (E2.7). 
No caso deste exemplo concreto, pode-se também sublinhar aquilo que o participante designa como estratégia de defesa, quando se refere ao trabalho com os alunos, como uma tática para fazer face às contrariedades.

\begin{abstract}
"Eu, para fazer qualquer coisa a nível profissional tenho que estar muito apaixonada por aquilo e eu tive outras oportunidades de trabalho e vim para a profissão de professor por paixão, mesmo. Eu gosto muito dos miúdos, gosto muito do contacto. Acho que um profissional como nós não envelhece nunca mais, porque andamos aqui com a maralha, conhecemos os gostos deles, as músicas deles, percebemos as palavras que estão na moda. Nós não envelhecemos e isso para mim é uma maravilha. O poder beber dos miúdos aquilo que nos trazem de novo, todos os dias, essas coisas, para mim é uma coisa fantástica. Eu sou de facto uma apaixonada, e não estando apaixonada, para mim é muito difícil. Para além das minhas aulas, para além dos meus tempos letivos, todo o resto é tão penoso que tu não imaginas." (E2.8)
\end{abstract}

Discurso que dispensa comentários, pois é uma declaração de amor à profissão docente.

O desacordo com as políticas educativas é uma componente muito comum em várias situações, e a referência a esse tema, surge, invariavelmente, num conteúdo de crítica, discordância e oposição. A dimensão política é determinante na forma como o exercício da docência se tem alterado, uma vez que são instrumentos legislativos que operam por detrás dessa mesma realidade.

Esse sentimento de desencanto com a profissão, ou com a realidade que a profissão vive atualmente, surge relacionado com as opções políticas e ideológicas, como refere E2.2, que não hesita no momento de atribuir responsabilidades

"às medidas governativas dos vários governos que têm por cá passado. Que têm desvalorizado a profissão, que têm tirado a autoridade do professor, que têm tirado a autonomia das escolas."

Pode-se mesmo afirmar que se trata de uma palavrachave com um grande valor semântico, pois caracteriza os sentimentos dominantes na classe docente.

"Para mim, diz-se numa simples palavra: desencanto. Estou desencantada. Fui para o ensino por paixão e essa paixão tem vindo a morrer, contrariamente à disciplina que leciono. Portanto, continuo apaixonada pela matéria que posso ensinar e que tento transmitir. Na realidade, no dia a dia, vejo-me confrontada com tanta coisa (?), lá está a burocracia, o sistema, a falta de meios, a falta de condições nas escolas... que tudo isso torna-se desmotivador." (GD2.1).
Apesar de tudo, há a crença de que pode haver uma mudança e uma rutura com a realidade, uma metanarrativa que inspira e que faz mover quem acredita em dias melhores e não desiste de um sonho, nesse caso concreto, o sonho de ser professora,
"Mas eu tirei o curso para ser professora por alguma razão, queria ser professora e quero ser professora. Sou mais teimosa do que eles! Tem sido assim, mas eu acredito sempre que amanhã é um dia melhor! Não é pelas políticas que há, mas acredito que mereço a estabilidade. Pode haver rutura de politicas, esperamos bem que sim." (E2.3).

A desvalorização social da profissão culmina com muito do que aqui foi dito. Curiosamente, os participantes fazem referência aos exemplos do passado, como sejam os dos seus professores, estabelecendo um termo comparativo entre a forma como estes viviam a profissão e as condições conhecidas e vivenciadas hoje em dia.

\begin{abstract}
"Quando eu comecei a dar aulas, tinha outra ideia, se calhar contagiado pelos professores que eu tive, que agora passo por eles e são pessoas sãs. Eu não sei se vou ficar são, quando for reformado, nem sei se tenho direito a reforma, nem nada, mas passo por eles e tenho imenso respeito por eles (...). Mas a escola de antigamente já não tem nada que ver com a escola de agora. Os valores, a imagem daquele professor que era considerado pelas pessoas, a projeção social. Não estou nisto por projeção social, estou nisto por duas razões principais, porque gosto de música e porque gosto de ensinar, gosto dos miúdos, mas pronto, eu acho que estou nisto por vocação." (E2.6)
\end{abstract}

Numa outra vertente, essa comparação também se faz numa perspectiva de desenvolvimento profissional, que leva à questão do controle sobre os processos de trabalho, ligado também à colonização do tempo por múltiplas tarefas, que colocam em causa uma dimensão intelectual da profissão.

\begin{abstract}
Quando olhávamos para trás e pensávamos nos nossos professores, eles viviam um pouco mais tranquilos, sem dúvida, e isso em muitos aspetos. Tinham mais qualidade de vida, mas tinham tempo para fazer pesquisa, para melhorar os seus conhecimentos, para fazer as suas leituras...
\end{abstract}

Por tudo o que foi referido e analisado, verificou-se que há várias dimensões que têm implicações emocionais na forma de viver e sentir a profissão. Estas, inevitavelmente, possuem um quadro de referência no qual se inscreveram as expetativas dos docentes no momento em que decidiram ser professores. Pelo contacto e pelas entrevistas que foram realizadas, pode-se dizer que 
muitos deles, porque referiram, escolheram a profissão de professor por paixão ou por vocação.

A desmotivação possui um significado que inunda o discurso do professorado e tem diversas causas, muitas das quais são abordadas neste trabalho. As dificuldades surgidas repetidamente levam a que muitos dos docentes se sintam sem força anímica para continuar.

"Se há funcionários públicos, e há muitos, que sempre trabalharam por uma questão mais de ética e por acreditarem no espírito de missão são os professores. $E$ há muitos, muito mais do que aquilo que passa nos jornais. Os professores sempre estiveram na escola porque gostavam, porque eram minimamente respeitados, muitas vezes contra o sistema. Mas, agora, qual é a motivação que um professor tem quando, por exemplo, dá Ciências duas vezes por semana, qual é a motivação de um professor de Educação Física, como eu, quando nós já nos queixávamos há uns anos de que o programa, desde 1986, é do $1^{\circ}$ ano ao 12ㅇano, mas os alunos só tinham aulas a partir do $5^{\circ}$ ano. Os primeiros quatro anos já eram cortados e, agora, nem para nota conta. O programa continua a ser igual e o tempo continua a ser reduzido." (GD1.4)

Nesse caso concreto, a desmotivação prende-se com a desvalorização de algumas disciplinas, voltando outras ao seu estatuto de áreas nobres. Uma abordagem que voltou a ganhar força em particular com o ministro da Educação e Ciência, Nuno Crato.

A autonomia pedagógica, um dos pilares de sustento da identidade do professorado, foi praticamente aniquilada com a introdução de exames que se apresentam como forte mecanismo de controlo, numa lógica de prestação de contas, pelo que a perda de autonomia pedagógica é uma das consequências. O que se pode inferir do discurso da participante GD1.5, a seguir:

"Esta história da escola nasce no século. XIX. A escola, assim como a conhecemos, para grande parte da população, para os filhos dos operários, marcada por tempos e marcada por disciplinas, é uma coisa muito antiga. Não sei se há alguma instituição que tenha durado tanto tempo. No século. XX houve algumas experiências para mudar um bocadinho essa maneira de ser, das $8 h$ às $9 h$, Português, das $9 h$ às $10 h$, Matemática, etc., etc. Essas experiências acabaram por fracassar, acabaram por não se conseguir estender, independentemente de, agora, no séculoXXI, sabermos de países que vão entrar por outros modelos pedagógicos, como, por exemplo, a Finlândia. O que interessa aqui reter é que nós continuamos a manter a mesma velha instituição, marcada por disciplinas e por tempos, com a grande agravante, como os colegas aqui disseram, e que as aulas são cada vez mais desinteressantes. As aulas parecem aquilo que nós demos 40 anos atrás, quando não havia um único vídeo, acetatos, nunca... E eu lembro-me que, quando comecei a dar aulas, eu mostrava filmes ou mostrava acetados, e os meus alunos diziam-me: 'Eh, professora tão giro!'. Todos nós passámos por isso. Neste momento não há há tempo para passar filmes."

No mesmo sentido, GD2.6, avança com um exemplo semelhante:

"No outro dia, fui ver aquele filme sobre o Sebastião Salgado, e tinha passado fotografias daquelas aos meus alunos, mas é uma coisa que eu quase já nunca faço, porque não tenho tempo para isso. E mostreilhes para eles verem como era o trabalho brutal, ainda hoje, em pleno século XXI, em determinados sítios, com imagens da Serra Pelada. Mas eu quase que não consigo fazer isso, porque eu não tenho tempo, não tenho tempo para procurar as imagens que quero levar para uma aula, para debatermos nessa aula, porque o que eu tenho que dar é os adjetivos, as conjugações e não sei quê... Porque isso é que sai no Exame."

A autonomia também passa pela capacidade de pensar, refletir e tomar decisões. Nesse aspeto em particular, os docentes queixam-se de terem cada vez menos disponibilidade, e a consequência é que o seu papel acaba por se tornar obsoleto em relação às necessidades dos jovens deste tempo, que são os alunos que entram numa Escola, muito semelhante, de acordo com as palavras da participante que citámos anteriormente, à escola do século XIX:

\begin{abstract}
"Eu aí há tempos, num encontro, já não sei dizer onde, ouvi um dos oradores dizer que uns anos atrás os professores eram os que traziam a novidade. Portanto o professor (...) conhecia, não é? Neste momento é o professor que não sabe mexer naquela coisa que anda assim com o dedo, não é? A era tecnológica que acontece cá fora da escola não tem a proporção que deveria ter dentro da escola para as aprendizagens e para a qualidade do ensino. Não há um desfasamento muito grande e isto (...) eu penso que é intencional. A profissão de professor, para além desses governos que têm implementado essas medidas todas, a profissão de professor é muito perigosa, porque os professores podem pensar, se tiverem tempo, se tiverem forma de construir as suas aulas, de elaborar..." (GD1.4)
\end{abstract}

A participante referida anteriormente defende a intencionalidade dessas medidas, precisamente no sentido de tornar os cidadãos menos interventivos e instrumentalizando a profissão docente com essa orientação.

As tendências de resposta que identificamos no âmbito dessa temática são as que se seguem. 

A. Descomprometimento com a profissão
B. Revolta
C. Desencanto
D. Desacordo com as políticas educativas
E. Compromisso com os alunos
F. Desvalorização social da profissão
G. Desmotivação
H. Perda de autonomia pedagógica

\section{CONSIDERAÇÕES FINAIS}

Neste cenário em que se desenvolve a profissão docente, pôde-se observar e descrever conquistas parcelares e transições perturbantes na profissionalidade. Esse processo tem-se consolidado na fabricação de identidades, no sentido de que a fabricação é um constructo para produzir práticas de significação, como refere Foucault (1996). E estas consistem em novos modos de ser professor, que se caracterizam, de acordo com Ball (2003), ao mesmo tempo, pela resistência e pela capitulação.

Os tempos vividos atualmente na educação são difíceis e ambíguos. Pode-se dizer mesmo que são de risco para o professorado, pois aqueles que têm mais antiguidade, não se revendo com esses novos discursos e exigências, aposentam-se na primeira oportunidade, ou contam ansiosamente os dias que lhe faltam para se aposentar. Os que se posicionam a meio de carreira procuram estratégias de sobrevivência, e os mais novos, confrontados com a dureza do acesso a um trabalho com direitos e estabilidade profissional, constroem estratégias de adaptação a percursos que se revestem de incerteza.

As implicações emocionais, na forma como é vivida e sentida a profissão, são pontuadas por sentimentos como o desencanto, a desmotivação e a revolta. Estes decorrem de um profundo desacordo com as políticas educativas que, segundo os participantes, têm originado um processo de erosão do estatuto social da profissão. Essa constatação retrata, em grande parte, a perda de uma característica fundamental da profissão docente e das chamadas profissões liberais: a autonomia pedagógica. Esta, por um lado, vem das inúmeras demandas que recaem em cima da profissão; por outro, surge dos mecanismos de controlo subjacentes ao exercício da profissão, que levam a um descomprometimento profissional, só amenizado pelo forte apelo de um compromisso que ainda é priorizado: as aprendizagens dos seus alunos.

A descrição dos sentimentos que se foi desocultando, a partir da análise efetuada, permite compreender que os docentes vivem a sua vida profissional de forma fragmentada, com extremos que se deslocam entre a paixão e o desencanto.

As ilações a tirar apontam para um desafio que, naturalmente, compreende a vontade e a predisposição do grupo profissional docente para condicionar os decisores políticos no sentido da valorização profissional e de uma melhoria das condições de trabalho e de exercício profissional. E isso pode corresponder a uma intervenção de maior qualidade e potenciadora do desenvolvimento de competências profissionais. A capacidade de manter a unidade e a resistência em face das forças manipuladoras vigentes - assentes numa lógica neoliberal que à educação atribui um valor de mercado - é a resposta fundamental que urge priorizar, numa lógica de contraposição às tentativas de perpetuação da ideologia dominante (ROSA, 2015).

\section{REFERÊNCIAS}

BALL, S. (2003). The teacher's soul and the terrors of performativity. Journal of Education Policy, v. 18, n. 2, p. 215-228. https:/doi.org/10.1080/0268093022000043065

BENAVENTE, A. et al. Crise de (?) austeridade e educação em Portugal (2011-2014). Investigar em Educação - II ${ }^{a}$ série, n. 3. p. 49-62, 2015.

BOGDAN, R.; BIKLEN, S. Investigação qualitativa em educação. Uma introdução à teoria e aos métodos. Porto: Porto Editora, 1994.

BÓIA, J. Educação e sociedade. Neoliberalismo e os desafios do futuro. Lisboa: Edições Sílabo, 2003.

DAY, C. et al. The personal and professional selves of teachers: stable and unstable identities. British Educational Research Journal, v. 32, n. 4, p. 601-616, 2006.

DENZIN, N.; LINCOLN, Y. Planejamento da pesquisa qualitativa - teorias e abordagens. Porto Alegre. Artmed, 2006.

DUBAR, C. La socialization. Construction dês identités sociales et profissionelles. Paris: Armand Colin, 1991.

ESTEVE, J. Identidad y desafíos de la condición docente. In: El oficio de docente: vocación, trabajo y profesión en el siglo XXI. Buenos Aires, 2006.

FOUCAULT, M. Vigiar e punir. Petrópolis. Vozes, 1996.

GARCIA, M. et al. As identidades docentes como fabricação da docência. Educação e Pesquisa, v. 31, n. 1, p. 45-56, jan.abr. 2005. https:/doi.org/10.1590/S1517-97022005000100004

GLAUSER, B.; STRAUSS, A. The discovery of grounded theory: strategies for qualitative research. Chicago: Aldine, 1967.

HYPOLITO, A. Trabalho docente, profissionalização e identidade: contribuição para a constituição de um campo de estudo. Educação em Revista, Belo Horizonte, n. 37, p. 123-138, 2003.

HYPOLITO, A. et al. Reestruturação curricular e autointensificação do trabalho docente. Currículo sem Fronteiras, v. 9, n. 2, jul.-dez. p. 100-112, 2009. 
HUSSERL, E. La Idea de la fenomenología. Madrid. Fondo de Cultura Económica de España, 1982.

LAWN, M. Os professores e a fabricação de identidades. Currículo sem Fronteiras, v. 1, n. 2, p. 117-130, jul.-dez. 2001.

MILES, M.; HUBERMAN, A. Qualitative data analysis: an expanded source book. London: Sage Publications, 1994.

RICOEUR, P. Na escola da fenomenologia. Trad. Ephraim Ferreira Alves. Petrópolis: Vozes, 2009.

ROSA, M. Ser professor: inquietações e desafios. A página da educação online. Disponível em: $<$ http://www.apagina.pt $/$ ?aba $=6 \&$ cat $=502 \&$ do $c=15115 \& \mathrm{mid}=1>$. Acesso em: 05 out. 2015.
SANTOS, B. Renovar a teoria crítica e reinventar a emancipação social. São Paulo. Boitempo, 2007.

SANTOS, B. Portugal - ensaio contra a autoflagelação. Coimbra. Almedina, 2011.

SANTOS, B. Reinventar las izquierdas? In: CORAGGIO, J.; LAVILLE, J. (orgs.). Reinventar la izquierda en el siglo XXI: hacia un diálogo norte-sur. Quito: Instituto de Altos Estudios Nacionales (Iaen), 2014. p. 157-179.

TOURRAINE, A. Après la crise. Paris. Seuil, 2010.

Submetido em 27/10/2015

Aprovado em 08/06/2016 